\title{
Air-Side Fouling of Compact Heat Exchangers for Discrete Particle Size Ranges
}

\section{R. HAGHIGHI-KHOSHKHOO}

Power and Water Institute of Technology, Tehran, Iran

\section{F. M. J. MCCLUSKEY}

Laboratoire des Ecoulements Geophysiques et Industriels, Université Joseph Fourier, Grenoble, France

The industrial problem of the air-side fouling of compact heat exchangers has been studied in a laboratory wind tunnel for particles in the $\mu \mathrm{m}$ to $\mathrm{m} \mathrm{m}$ range. The measurements of pressure drop across the exchanger as well as the quantification and classification of the particles blocked by and passing through it were taken for discrete ranges of particle sizes. Observation showed that the blocked particles either drop to the wind tunnel floor, remain on the outside surface of the exchanger (falling to the floor once the wind velocity drops), or penetrate a short distance into it according to the relative values of fin spacing and particle size. These last are the most detrimental to exchanger performance. There is a critical particle size for which this penetration is maximal. A brief non-dimensional geometrical analysis allows one to predict this critical size range for any finned exchanger. It has been found to be between 0.5-0.7 times the diameter of the largest sphere that can be inscribed between the fins. Confirmation of this was found with a second exchanger. The addition of humid conditions within the tunnel or on the exchanger itself did not modify these values. Subtracting the pressure drop due to the clean exchanger from the total measured value confirms that the foulant acts like an extra mechanical filter in series with the exchanger. This is quite understandable given the short penetration length of the particles (up to $3 \mathrm{~mm}$ ). Finally, the effects of a closed wind tunnel test section on the measurements for nonisothermal conditions in the exchanger are discussed.

\section{INTRODUCTION}

Reduced performance due to the fouling of the compact heat exchanger of an industrial vehicle may necessitate it being removed from service for cleaning, a potentially time-consuming process. The more polluted the air is locally, the more often the vehicle is out of action, resulting in increased operating costs. Fouling is a dynamic process that evolves continually until equilibrium is reached and the exchanger needs to be cleaned. This can take hours, weeks, or months, depending on the environment.

Much work has been carried out on the phenomena involved in liquid-side fouling within tubes, and these are now fairly well

The authors would like to thank the French and Iranian governments for cofinancing this project via the SPHERE organization. The work was greatly aided by the donation of compact heat exchangers by Dr. Bruno Hamery of Valeo.

Address correspondence to Professor F. M. J. McCluskey, Laboratoire des Ecoulements Geophysiques et Industriels, Université Joseph Fourier, BP 53, 38041 Grenoble cedex 9, France; E-mail: Francis.Mc-cluskey@ujf-grenoble.fr understood. The term "air-side" fouling refers to the build-up of debris and/or particles on the external surface of the exchanger, most importantly, between the fins. Studies to date generally cover the effects on the heat transfer coefficient of micrometricsized particles; little attention has been paid to the millimetric range, which has no significant effect on it. Cowell \& Cross [1] showed that for off-road vehicles, about $7 \%$ of the particles involved in fouling were of this larger size. Research on larger particles has also been carried out by Bott and coworkers [2], Lankinen et al. [3], and Seigel and Nazaroff [4]. Cowell \& Cross tested 22 different exchangers in a wind tunnel under "oily" conditions to enhance adherence of the particles to the surface. They found that most of the foulant remained on the front of the exchanger, resulting in a high pressure drop due to the supplementary (effective) filter that it formed there. They observed no great modification to the heat transfer measurements at constant air speed. They also defined a fouling coefficient which accounts for the pressure drop due solely to the foulant:

$$
\mathrm{F}=\left(\Delta \mathrm{p}_{\text {total }}-\Delta \mathrm{p}_{\text {exchanger }}\right) / 1 / 2 \rho v^{2} .
$$


As fouling increased, $F$ showed little variation with air speed. Similar results and conclusions were found by Bott et al. [2] in their wind tunnel tests. However, Lankinen et al. [3] found that the thermal performance of the exchanger could be reduced by up to $18 \%$ following fouling, a result they did not explain. Seigel and Nazaroff [4] examined the front surface of a number of exchangers fouled in a dusty environment by particles of less than $10 \mu \mathrm{m}$ and found a significant quantity of much larger size particles within the foulant. They concluded that the presence of bigger particles increased the rate of fouling. Once more, the foulant did not penetrate into the heart of the exchanger. In all of the above cited works, the air speed was fixed at values between 1 and $5 \mathrm{~m} / \mathrm{s}$.

\section{EXPERIMENTAL PROCEDURE}

The test section of the wind tunnel used for the experiments had a $40 \mathrm{~cm} \times 40 \mathrm{~cm}$ cross-section and was made of plexiglass, allowing for the visualization of the fouling process. Exchangers were introduced via a lateral slot, which was then insulated from the outside to prevent air leakage. Pressure tappings were drilled into the tunnel floor upstream and downstream of the exchanger and were connected to a differential pressure manometer. In a number of experiments, the exchanger was wetted using a water spray from a side window. Air velocity was measured using a Pitot tube. On the liquid side of the exchanger, thermocouples were set in the entrance and exit flows. A thermostated bath was used for pumping and heating the water for the exchanger.

Particles were introduced into the flow through the test section roof just over $1 \mathrm{~m}$ upstream of the exchanger. Numerous experiments were carried out for different rates of particle introduction. The particles were introduced in discrete lots rather than continuously due to the technical difficulties and costs of such a setup. A given total mass $M$ of single-size particles was divided equally into $\mathrm{n}$ distinct lots and introduced in succession into the wind tunnel. The greater the number $n$, the closer the procedure approaches the continuous injection case. The measurements showed that for $\mathrm{n}$ varying from 3 to 20 , the results were very reproducible, showing a variation of less than $5 \%$ overall. The conclusion that the rate of introduction had little or no effect on the fouling process apart from duration to saturation is expected, and the mass of foulant on the exchanger does not change from one case to the next. The particles themselves were wood shavings sorted into different size ranges using sieves.

Two exchangers were studied, their characteristics shown in Table 1. The particle size ranges were chosen as a func-

Table 1 Relevant exchanger characteristics

\begin{tabular}{lll}
\hline & Exchanger A & Exchanger B \\
\hline Fin density/100 mm & 44 & 95 \\
Fin spacing at base & $3 \mathrm{~mm}$ & $1.38 \mathrm{~mm}$ \\
Fin spacing at summit & $1.6 \mathrm{~mm}$ & $0.64 \mathrm{~mm}$ \\
Fin length & $18.5 \mathrm{~mm}$ & $7.6 \mathrm{~mm}$ \\
\hline
\end{tabular}

Table 2 Particle range sizes for both exchangers

\begin{tabular}{ll}
\hline Exchanger A & Exchanger B \\
\hline $\mathrm{d}<0.8 \mathrm{~mm}$ & $\mathrm{~d}<0.25 \mathrm{~mm}$ \\
$0.8<\mathrm{d}<1.25 \mathrm{~mm}$ & $0.25<\mathrm{d}<0.5 \mathrm{~mm}$ \\
$1.25<\mathrm{d}<1.85 \mathrm{~mm}$ & $0.5<\mathrm{d}<0.8 \mathrm{~mm}$ \\
$1.85<\mathrm{d}<2 \mathrm{~mm}$ & $0.8<\mathrm{d}<1.25 \mathrm{~mm}$ \\
$2<\mathrm{d}<3.15 \mathrm{~mm}$ & $1.25<\mathrm{d}<1.6 \mathrm{~mm}$ \\
$3.15<\mathrm{d}<4 \mathrm{~mm}$ & \\
\hline
\end{tabular}

tion of the fin spacing, it being obvious that particles much larger than this will not contribute to fouling but fall to the tunnel floor following impact. It was also decided initially to discretize over six size ranges for exchanger $\mathrm{A}$; those for $\mathrm{B}$ were determined after analyzing the results from exchanger $\mathrm{A}$ (see Table 2).

Experiments could be divided into four groups on each exchanger: isothermal wet and dry surfaces, and non-isothermal wet and dry surfaces. As all previous results in wind tunnel tests show that fouling had hardly any effect on heat transfer, the main body of results concern the isothermal case.

Wind velocities were chosen at 2, 2.5, 3, 3.5, 4, 4.5, and $5 \mathrm{~m} / \mathrm{s}$. The pressure drop measurement of interest is that due to the foulant only: the evolving total value minus that for the clean exchanger (i.e., $\Delta \mathrm{p}_{\text {total }}-\Delta \mathrm{p}_{\text {exchanger }}$ ). This is proportional to the fouling factor $F$. Pressure drop is measured continually during particle introduction. Observation shows that the particles either passed through the exchanger, were blocked on the exchanger surface, or rebounded to the tunnel floor upon impact. Each of these components was weighed and compared to the amount introduced. Photographs of the surface were also taken for analysis. Gravitation does affect the passage of particles from the point of introduction $1 \mathrm{~m}$ upstream of the exchanger. A small zone on the upper part of the exchanger remains clear of particles. The extent of this "dead zone" is measured for each set of experiments depending on air speed and particle size (or mass) and blocked off. All results refer to the "active" or fouled area of the exchanger surface.

\section{RESULTS}

\section{Pressure Drop Due to Foulant}

As indicated, pressure measurements refer to the total value across the fouled exchanger minus the clean exchanger value. Typical results for this are shown on Figure 1 for a wind velocity of $4 \mathrm{~m} / \mathrm{s}$ for different particle sizes (see Table 2, exchanger A).

Referring to the particle size ranges as A1 (smallest) to A6 (largest), it is seen that the A1 particles do not cause any drop in pressure, indicating that they all pass through the exchanger in dry conditions. In fact, several hundred grams of A1-size particles were introduced with the aim of checking whether or not a surface deposit formed on the fins. In such a case the pressure 


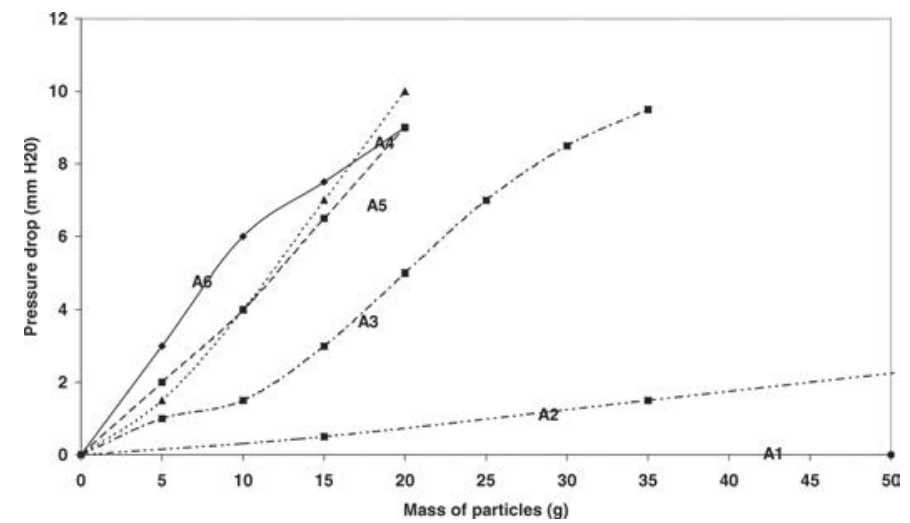

Figure 1 Pressure drop due to the foulant as a function of the mass of particles introduced for different size ranges.

drop measurements would only evolve very slowly. However, no such effect was observed or measured. The rate of foulant buildup increases with particle size from range A2 onwards, with the largest sizes showing a saturation tendency; this suggests that the majority of these particles are blocked by the exchanger and thus contribute to the pressure drop. The main variation occurs between A2 and A4. For each range, the pressure drop varies more or less linearly with the mass of particles introduced. In the presence of humidity, the pressure drops increase slightly, including for the A1 case. This was so while the liquid film was present on the exchanger surface. As it dried, the pressure drop values tended toward the "unwetted" values.

\section{Mass Distribution of Particles}

Initial observation showed that of the introduced particles, a proportion remains blocked on the surface contributing to pressure drop, while a further amount rebounded from the surface and dropped to the tunnel floor. Therefore, from the total mass of particles introduced, it is necessary to subtract this mass on the tunnel floor because it makes no contribution to pressure drop. This is removed via the side window while the air velocity is kept constant, and weighed. Following this, the air velocity is reduced to zero, resulting in a fall to the floor of a significant mass of particles from the exchanger surface. This mass is weighed. The particles remaining on the exchanger are then removed (not without difficulty!) and also weighed. The missing mass represents the particles that pass through the exchanger and are lost to the exterior of the system. Clearly, these results are taken at the end of the particle introduction process and correspond only to the final point on the pressure drop curves. It is not possible to take these measurements as the phenomenon evolves; however, it is likely that the tendency is linear and mirrors the pressure drop evolution.

It can be seen in Figure 2 that the percentage of particles blocked by the exchanger with respect to the total mass of particles injected increases with particle size. Beyond the A6 range, $100 \%$ of the particles are blocked. The mass of fouling particles (i.e., those on the exchanger contributing to pressure drop) sat-

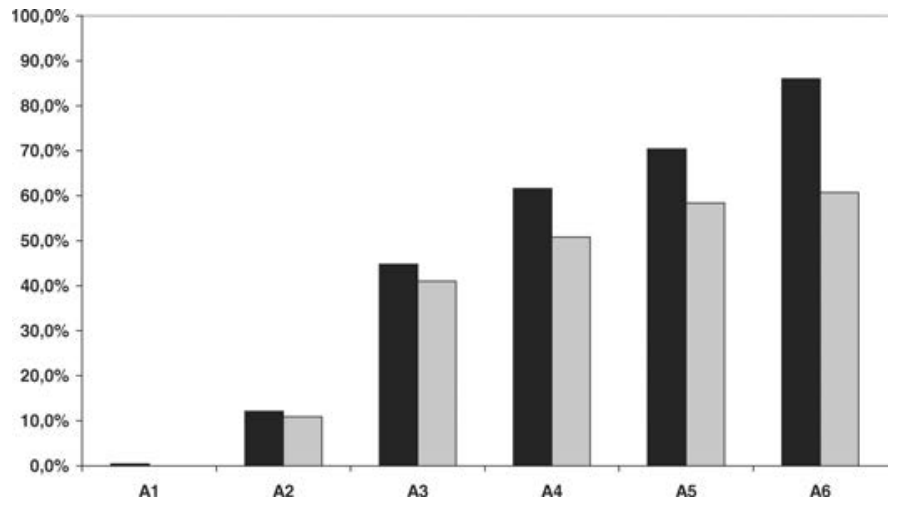

Figure 2 Percentage of introduced particles blocked by exchanger (black), and those contributing to pressure drop (gray), that is, remaining on surface, as a function of particle size range (see Table 2).

urates with particle size, indicating that larger particles rebound more and more from the exchanger surface as it is covered with foulant. This saturation corresponds to a constant pressure drop across the fouled exchanger, a conclusion consistent with the results shown in Figure 1, where the same pressure drop measurement is observed for the A4, A5, and A6 particle ranges. Some extrapolation is necessary to understand this apparent saturation fully. For the case of very small particles, there is no fouling (e.g., A1); however, above some threshold, it will begin and increase with particle size (from A2 on). At the other end of the scale, very large particles all rebound from the surface and fall to the floor. As particle size is decreased, more and more will settle on the surface. There is therefore a range of particles between these two extremes where fouling will reach a maximum level. The results presented in Figure 2 are truncated close to this maximum, giving a false impression of saturation. The overall expected tendency is shown schematically in Figure 3.

As mentioned previously, it was observed that the fouling particles were divided into two distinct groups according to their

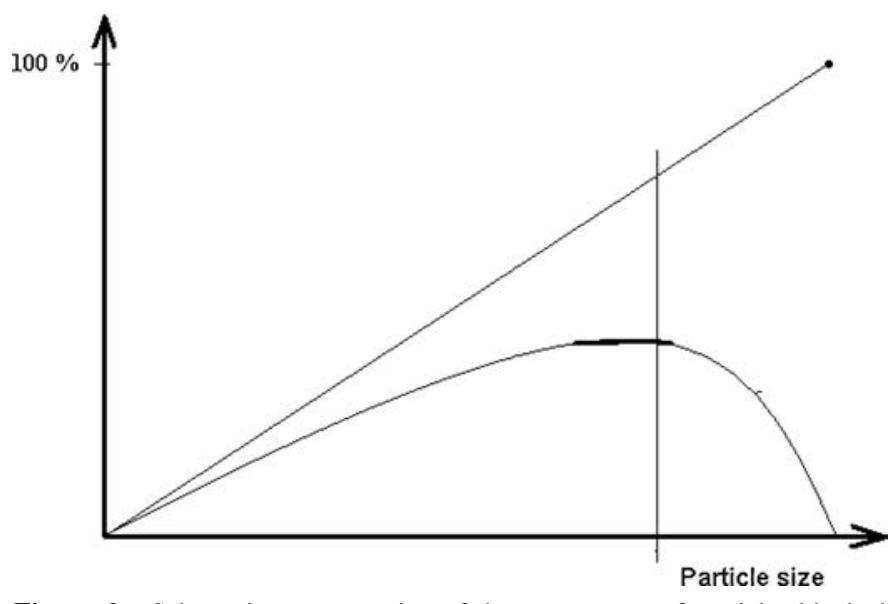

Figure 3 Schematic representation of the percentages of particles blocked by the exchanger within the wind tunnel (straight line) and those that foul the exchanger (lower curve) as a function of particle size. The vertical line indicates the cut-off for the histogram of Figure 2. 


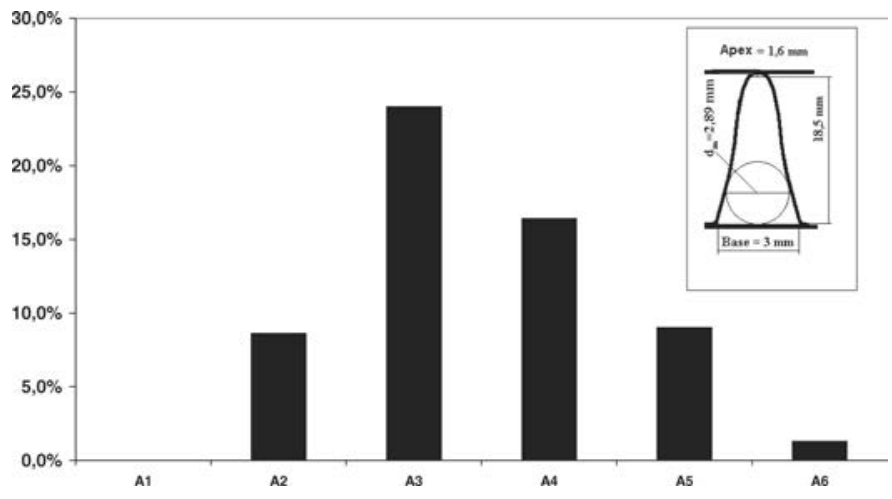

Figure 4 Percentage of particles penetrating into exchanger (i.e., sub-surface penetration) as a function of their size; exchanger A. Inset: fin geometry.

adherence to the surface of the exchanger: those that fall when the air velocity is zero (external foulant) and those that penetrate into it (sub-surface fouling). Both contribute to pressure drop, but it is the latter that presents the most problems for any compact heat exchanger. It is necessary to ascertain the size range of these particles and find a relationship between it and the fin geometry of the exchanger.

Interpretation of the results in terms of ratios needs to be carried out rather carefully. By taking the mass of sub-surface particles as a proportion of blocked or fouling particles, the resulting curve is strictly decreasing with rising particle size, giving the impression that the $\mathrm{A} 2$ or $\mathrm{B} 2$ scale is the most penetrating. However, in referring to Figure 3, it is clear that the quantity $\mathrm{M}_{\mathrm{ss}} / \mathrm{M}_{\text {blocked }}$ will be greatest for the smallest (blocked) particle size. It is important to find the size corresponding to the maximum of the sub-surface fouling results. The curve of interest is therefore the ratio of $\mathrm{M}_{\mathrm{ss}}$ to $\mathrm{M}_{\text {total }}$, as shown in Figures 4 and 5. There is a clear maximum value for the A3 range of particles (and for B3 on the second exchanger).

The results were quite similar when the exchanger surface was wetted.

The size ranges $\mathrm{A} 3$ and $\mathrm{B} 3$ (i.e., those for which penetration into the exchanger is greatest) will be referred to as "critical." Those of a smaller size tend to pass through the exchanger, while larger ones get blocked on the outside surface. The penetration

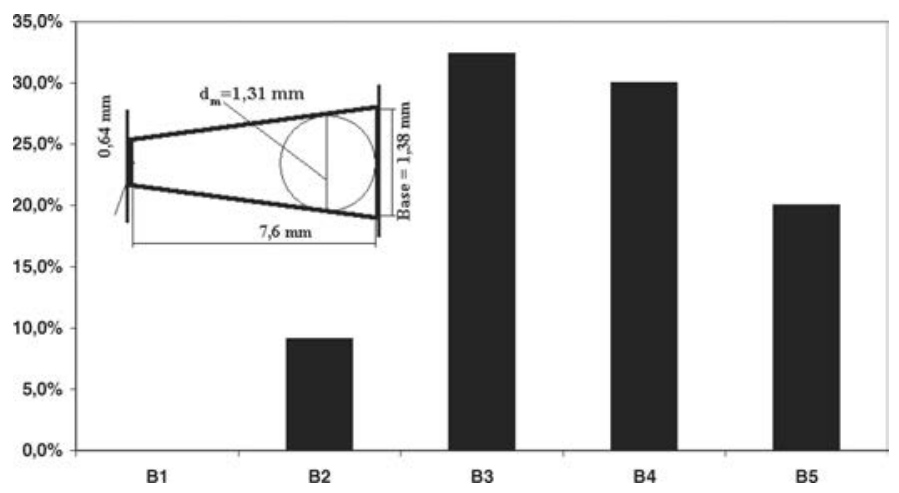

Figure 5 Percentage of particles penetrating into exchanger (i.e., sub-surface penetration) as a function of their size; exchanger B. Inset: fin geometry. depth is surprisingly small, being only about 3 or $4 \mathrm{~mm}$. This is also consistent with measurements of the pressure drop, the foulant forming a physical screen in front of the exchanger. Observation showed that beyond this initial depth, there was no build-up of particles in the interior. Once any particle went beyond a $4 \mathrm{~mm}$ distance, it was transported out the rear side without any apparent hindrance. As the effective surface area through which a particle can pass diminishes with fouling, the constant flow rate of the air passing through the exchanger means that the air velocity through it increases where the surface is clean and drops where it is fouled. It is possible that higher velocities carry particles further (right through the exchanger), and eddying behind the foulant helps a deposit to build up locally, leaving the core free.

These critical particles enter into the inter-fin spacing and effectively reduce the area of passage for other particles that might not otherwise be blocked. They thus form "nucleation" sites for further fouling and will certainly influence the behavior of smaller size particles there. It is clear also that the critical particle size will be related to the fin spacing for any given exchanger.

\section{Particle Size and Fin Spacing}

Experiments were initially carried out on exchanger A, with the range of particle sizes in Table 2 chosen without prior knowledge of the possible outcome. Analysis of the results led the authors to attempt to predict the size range of the "critical" particles. The smallest particle that will not automatically pass through the exchanger without hindrance is chosen to have a spherical diameter of half the minimum distance between fins. The largest particle that could penetrate into the exchanger corresponds to the hydraulic diameter of the inter-fin area: $d_{H}=4 \times$ area/perimeter. The measurements showed this to be a very good prediction of what happens. All larger particles either rebounded off the exchanger onto the floor or remained against the outside surface while the velocity was non-zero.

The method of predicting the critical particle size was as follows. Given the fin geometry of the exchanger, it is possible to evaluate the diameter $d_{m}$ of the largest sphere that can be inscribed in the inter-fin spacing (see insets on Figures 4 and 5). Most particles smaller than $1 / 2 \mathrm{~d}_{\mathrm{m}}$ will pass through the exchanger. Two particles of a diameter less than or equal to $1 / 2 \mathrm{~d}_{\mathrm{m}}$ arriving simultaneously should also pass through. Larger particles will be blocked, though not necessarily in the subsurface region. The limiting value is taken as the diameter of the particles of which the projected area is half that of the circle of diameter $\mathrm{d}_{\mathrm{m}}$. A similar reasoning can be carried out for several particles arriving simultaneously [5]. Based on the case of two particles (the probability of three or more particles arriving simultaneously at the same position is slim), the critical particle range is therefore $1 / 2 \mathrm{~d}_{\mathrm{m}}<\mathrm{d}_{\text {crit }}<0.707 \mathrm{~d}_{\mathrm{m}}$. Taking the critical value to be (arbitrarily) halfway between these gives $d_{\text {crit }}=0.6 d_{m}$.

For exchanger A, this gave a diameter of $1.75 \mathrm{~mm}$, which corresponds well with the measurements in Figure 4. This predictive 


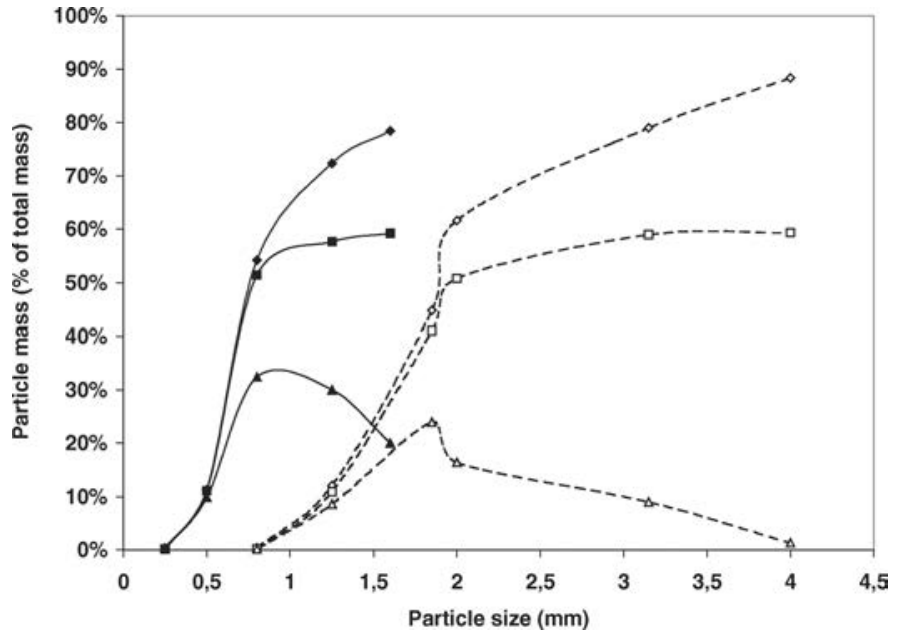

Figure 6 Masses of recovered particles as a percentage of the total introduced as a function of particle size. The top curves (diamond) represent those blocked, the middle (square) represent those contributing to pressure drop, and the bottom (triangle) represent sub-surface fouling (left: exchanger B, full lines; right: exchanger A, dashed lines).

method was then used to fix the ranges of particles to be examined for exchanger $\mathrm{B}$. The critical diameter was found to be $0.78 \mathrm{~mm}$. This is in the upper part of the range B3 $(0.6-0.8 \mathrm{~mm})$, suggesting that the range B4 $(0.8-1.3 \mathrm{~mm})$ will also contain a significant number of critical particles. This is borne out by the results (see Figure 5), where the maximum level of sub-surface fouling is at the larger end of the B3 range.

The mass of blocked and sub-surface particles relative to the total injected mass, plotted as a function of particle size, is shown in Figure 6 for both exchangers. The curves show similar tendencies. However, when both sets are non-dimensionalized by the appropriate diameter $\mathrm{d}_{\mathrm{m}}$, thus effectively eliminating the specific dimensions of the exchanger, the critical particle value becomes very evident (see Figure 7). This corresponds to the maximum value of sub-surface particle penetration and takes a value of $\mathrm{d} / \mathrm{d}_{\mathrm{m}}=0.63$, very close to the predicted value of 0.6 . The same result would have been found had the critical size been

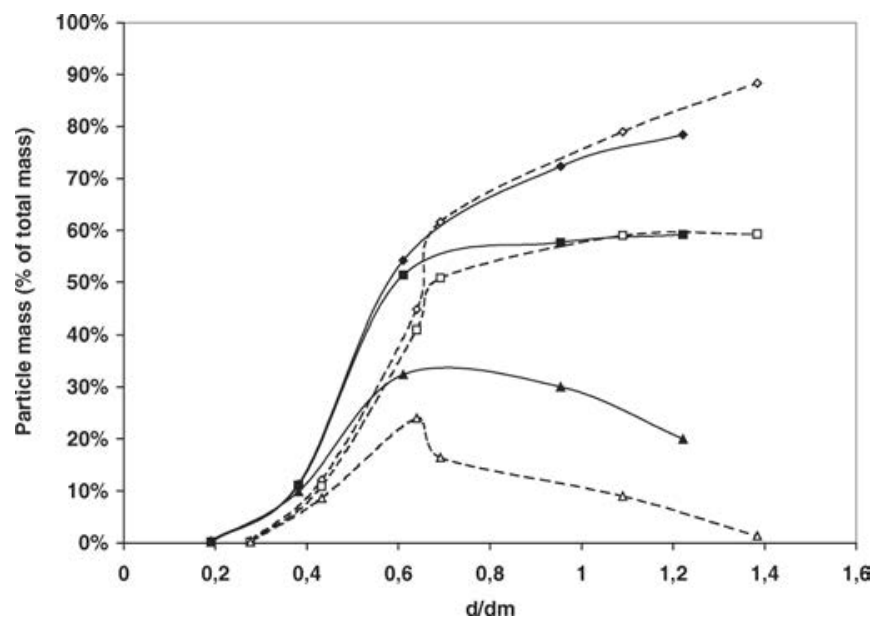

Figure 7 Results of Figure 6, as a function of non-dimensional particle size. used to non-dimensionalize the results. However, the value of $\mathrm{d}_{\mathrm{m}}$ is easier to obtain for any exchanger. It is fairly safe to say, even if only on the basis of measurements on two different compact heat exchangers, that once any exchanger geometry is known, it is possible to define the size range of the critical particle for sub-surface fouling.

The curves of Figure 7 are also independent of air speed in the wind tunnel (for velocities between 2 and $5 \mathrm{~m} / \mathrm{s}$ ), indicating that, at least over this range, geometrical effects dominate the fouling process.

The curves for sub-surface fouling correspond well with what is expected: smaller particles $\left(\mathrm{d} / \mathrm{d}_{\mathrm{m}}<0.2\right)$ pass through the exchanger, while larger ones $\left(d / d_{m}>1.0\right)$ remain on the external surface. The difference between the fouling and blocked particles in the figure represents the quantity that rebounds from the exchanger and fall to the tunnel floor. This percentage will evidently increase with particle size.

The percentage of particles that remain on the outer surface of the exchanger (and thus contribute to the pressure drop) appears at about $60 \%$ for $d / d_{m}>0.9$. This is a more difficult phenomenon to explain physically, particularly because the range of particle sizes tested was limited to $d / d_{m}=1.5$. The saturation within this range most likely corresponds to an initial surface build-up of foulant entraining a modification of the air flow in its immediate vicinity. The slight pressure drop that would be felt just downstream of the surface foulant particles within the exchanger is not going to be felt by a second or third layer of particles that deposit on the first. The balancing of the local pressure distribution will cause the later-arriving particles to fall off the surface despite the air flow pushing them toward it (i.e., gravitational effects will overcome local pressure forces).

\section{Fouling Factor}

It is now clear from the results that air-side fouling depends on geometrical considerations almost exclusively. The influence of fluid mechanics, thermal gradients, and humidity is very much secondary. The fouling factor F, defined earlier as the nondimensional foulant pressure drop, should reflect this. Figure 8 shows how $\mathrm{F}$ varies with air speed $\mathrm{V}$. Above a certain value of $\mathrm{V}, \mathrm{F}$ becomes constant, indicating that the foulant has taken the role of a grid or mechanical filter in front of the exchanger. The weakly decreasing value of $\mathrm{F}$ for the lower velocities was noted for all particle sizes below the critical value. Above this, F was constant for all $\mathrm{V}$. The explanation for this weak variation in $\mathrm{F}$ is probably that some amount of the smallest particles blocked at the surface are blown through the exchanger as air speed is increased.

$\mathrm{F}$ also increases in level as more foulant is added. The constant $\mathrm{F}$ values plotted as a function of the mass introduced into the tunnel correspond particularly well with the pressure drop measurements, a typical sample of which is shown in Figure 1. 


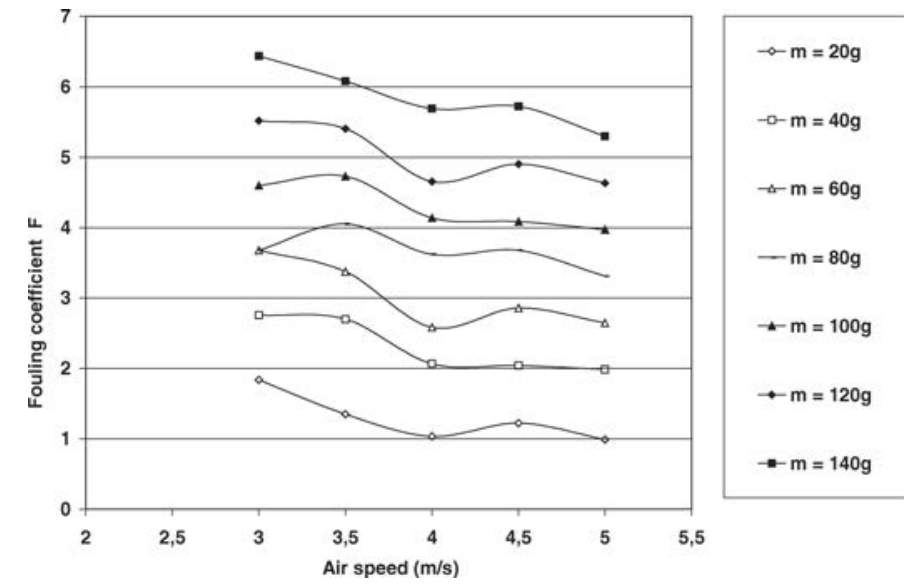

Figure 8 Variation of the fouling coefficient $\mathrm{F}$ with air speed for the size range B2: evolution for increasing mass. Similar curves are found for all size ranges for both exchangers.

\section{Non-Isothermal Tests}

Several series of tests were carried out to quantify the effects of fouling on heat transfer across the exchanger. The input temperature was fixed at either $60^{\circ} \mathrm{C}$ or $70^{\circ} \mathrm{C}$, with the flow rate set by a $3.5 \mathrm{~kW}$ thermostated bath. For a given air speed in the wind tunnel, the temperature drop did not change with increasing fouling, although the pressure drop did. A typical set of results are shown in Figure 9. This is easily explained. As the fouling is confined to the front of the exchanger, there is no modification of the surface state in the core (constant exchange coefficient). Secondly, the evacuated heat is proportional to the flow rate of air across the exchanger. This remains constant in a closed wind tunnel test section no matter what the extent of the fouling is.

This clearly does not reflect reality. A more appropriate form of testing needs to be defined that takes into account the fact that a fouled heat exchanger will deflect some of the oncoming air flow around it, thus reducing the air flow through the exchanger and, as a consequence, the evacuated heat. The simple expedient of opening a window in the tunnel at the side of the heat exchanger

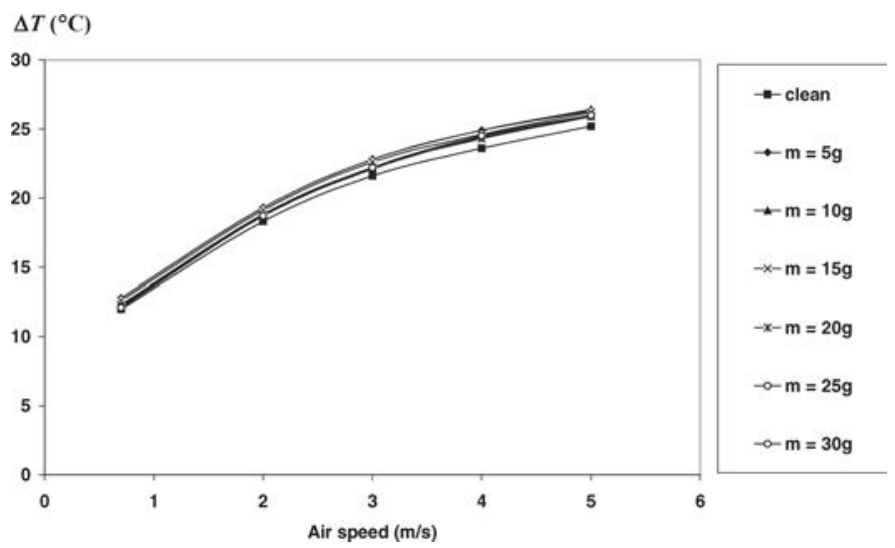

Figure 9 Influence of air-side fouling on the water-side temperature drop across exchanger $\mathrm{A}$ as a function of air speed. The curves cover fouled and clean surfaces.

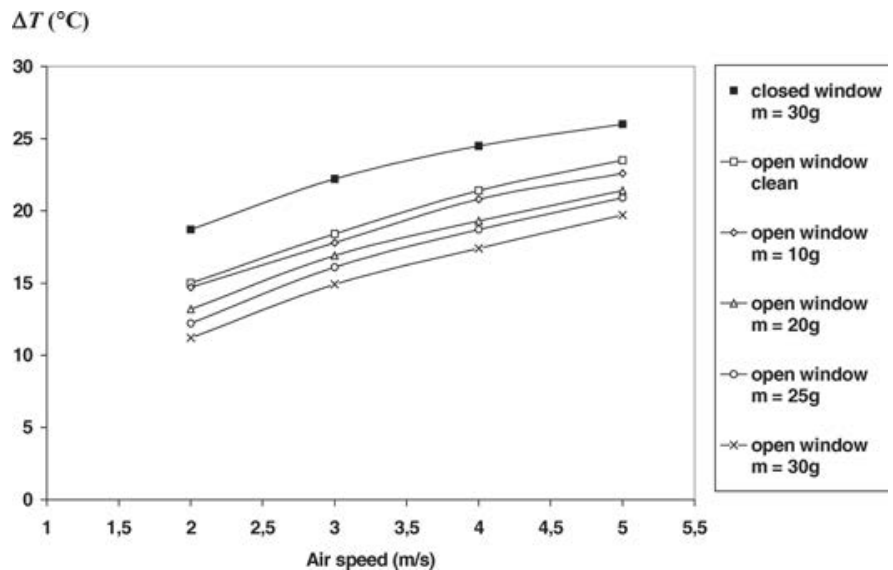

Figure 10 Evolution of the water-side temperature difference as a function of air speed for various levels of fouling - exchanger A with A3 size range foulant. The top curve represents the closed wind tunnel; all others cover the open tunnel case.

allows for the measurement of the effect of air flow deviation on temperature. Figure 10 shows how the water side temperature drop changes when the air flow is allowed to deviate. Of course, as fouling increases, so does this deviated air flow away from the exchanger, and the temperature drop falls even further. The drop is significant, even at these relatively weak levels of fouling (typically about $8^{\circ}-15^{\circ} \mathrm{C}$ ).

In conclusion, obliging the air flow to pass through the exchanger as in usual wind tunnel experiments will mask the heat transfer problem due to fouling, but it will not influence the pressure drop due to it. The problem of deviated air flow will be all the greater with very closely spaced fins, suggesting the possibility of an optimal spacing.

\section{CONCLUSION}

Depending on their relative size, particles approaching a compact heat exchanger either pass through without hindrance, are blocked over a shallow depth at the front, rest on the outer surface while the air speed is non-zero, or rebound from the surface and drop to the wind tunnel floor. Those that penetrate into the sub-surface region are the most detrimental to exchanger performance.

There is a critical particle size for which this penetration is maximal. This is found to be 0.6 times the diameter of the largest sphere that can be inscribed in the fin spacing.

The penetration depth is small, being only about 3 or $4 \mathrm{~mm}$. This is consistent with measurements of the pressure drop, the foulant forming a physical screen in front of the exchanger.

All non-isothermal testing of compact heat exchangers referred to in the literature was carried out with a constant flow rate of air. Fouling will not affect the thermal performance in such circumstances.

A fouled exchanger will deviate the air flow upstream, causing a part of that flow to bypass it. This will automatically have 
a significant detrimental effect on heat transfer, leading to overheating. Any non-isothermal testing of compact heat exchangers should take this into account. This, along with an analysis of binary mixtures of particles, should be the subject of future research.

\section{REFERENCES}

[1] Cowell, T., and Cross, D. A., Airside Fouling of Internal Combustion Engine Radiators, Paper no. 801012, SAE Trans, vol. 89, pp. 3179-3188, 1981.

[2] Bott, T. R., Fouling of Heat Exchangers. Elsevier, 1995.

[3] Lankinen, R., et al., The Effect of Air-Side Fouling on the Heat Transfer Efficiency of a Heat Exchanger with a Segmented Finned Tube, Int. Symp. Transport Phenomena 12, Istanbul, Turkey, 2000.

[4] Seigel, J., and Nazaroff, W. W., Modeling Particle Deposition on HVAC Heat Exchangers, Report no. LBNL-49339, Lawrence Berkeley National Laboratory, 2002.

[5] Graham, R. L., Lubachevsky, B. D., Nurmela, K. J., and Ostergard, P. R. J., Dense Packing of Congruent Circles in a Circle, Discrete Mathematics, vol. 181, pp.139-154, 1998. 